\title{
Design Optimization of Diffuser Augmented Wind Turbine
}

\author{
Ahmed M. Elsayed ${ }^{1, *}$ \\ 1 Mechanical Engineering Department, Faculty of Engineering, Fayoum University, Fayoum, 63514, Egypt
}

\begin{tabular}{l} 
ARTICLE INFO ABSTRACT \\
\hline
\end{tabular}

Article history:

Received 17 July 2021

Received in revised form 14 August 2021

Accepted 15 August 2021

Available online 26 August 2021

Keywords:

Wind turbine; diffuser; CFD; parametric study; simplex algorithm; optimal shape

\begin{abstract}
The wind turbine power decreases at low wind speed. A flanged diffuser plays a role of a device for collecting and accelerating the approaching wind, and thus the optimization of the diffuser shape presents an important way to enhance the wind turbine power. In this work, a numerical parametric study was conducted on the diffuser to obtain the initial optimum form of flanged diffuser. Then, the Simplex algorithm is used to obtain the optimal diffuser shape starting from the obtained initial shape. Finally, the obtained optimum diffuser shape is used with conventional wind turbine blade. The diffuser shape is defined by four variables: open angle, flange height, centerbody length, and flange angle. The numerical simulation of flanged diffuser is carried out using the "CFDRC package". The results indicated that, the optimum diffuser shape can be obtained using simplex algorithm which maximizes the entrance average velocity to reach 1.77 times wind speed. The power augmented by a factor about 2.76:5.26 of a selected small wind turbine using the obtained diffuser shape compared to that without diffuser.
\end{abstract}

\section{Introduction}

Wind power generation is proportional to the wind speed cubed. Therefore, a large enhancement in output power is brought about if it is possible to create even a slight increase in the velocity of the approaching wind to a wind turbine. The wind speed can be increased by utilizing the fluid dynamic nature around a structure or topography, namely if the wind energy locally can be concentrated, the output power of a wind turbine can be increased substantially.

The importance of the airfoil in diffuser design is significant. The lift achieved when using an airfoil increases the air mass flow through a diffuser for a given length-diameter ratio compared to a straight-wall diffuser. Aranake et al., [1] conducted a 3D CFD analysis to compare Diffuser geometries with airfoil cross sections. Four cross sections were computed; the Eppler E423, Selig S1223, NACA0006 (baseline design) and the FX 74-CL5-140. From a two-dimensional analysis of the flow fields, it was found that the Selig S1223 exhibited the best performance.

A multi-slotted diffuser is used to prevent separation within the diffuser. Bet and Grassmann [2] developed a shrouded wind turbine with a wing-profiled ring structure. It was reported that their DAWT showed an enhancement in power output by the wing system by a factor of 2 , compared to

\footnotetext{
* Corresponding author.

E-mail address: ams16@fayoum.edu.eg (Ahmed M. Elsayed)
}

https://doi.org/10.37934/cfdl.13.8.4559 
the bare wind turbine. Nagai and Irabu [3] investigated a convergent diveregent-type structure (i.e., the front part is a nozzle and the rear part is a diffuser) as a structure concentrating the wind energy, especially paying attention to the effect of the diffuser part.

Jafari and Kosasih [4] modeled a simple diffuser for a small turbine, 300 AMPAIR, in a virtual wind tunnel for a range of rotor rpm's at a constant wind speed to obtain tip speed ratios. Kosasih and Hudin [5] investigated the effect of different turbulence intensities on a DAWT and an equivalent bare wind turbine (NACA 63-210, $190 \mathrm{~mm}$ diameter) so as to measure their relative performance in terms of coefficient of performance and tip speed ratio. Mansour and Meskinkhoda [6] used the $k-\varepsilon$ RNG and Spalart-Allmaras turbulence models to study the flow fields around flanged diffusers using equal dimension flanged DAWT's, one with an inlet and the other without and the third with just a diffuser.

Abe and Ohya [7] carried out experimental and numerical investigations for flow fields of a small wind turbine with a flanged diffuser. To study the flow mechanism, mean velocity profiles behind a wind turbine were measured using a hot-wire technique. The results gave useful information about the flow mechanism behind a wind turbine with a flanged diffuser. In particular, a considerable difference was seen in the destruction process of the tip vortex between the bare wind turbine and the wind turbine with a flanged diffuser.

Matsushima et al., [8] studied the effect of diffuser's shape on the wind speed by simulation and showed that the wind speed in the diffuser was greatly influenced by the length (at certain expansion angle) and expansion angle (at certain length) of the diffuser, and maximum wind speed increased 1.7 times with the selection of the appropriate diffuser shape.

Unique research that was carried out intensively in the past is the examination of a diffuseraugmented wind turbine (DAWT) by Gilbert et al., [9], Gilbert and Foreman [10], and Igra [11]. In their studies, there was a focus on concentrating wind energy in a diffuser with a large open angle; a boundary layer controlled with several flow slots was employed to realize a flow that goes along the inside surface of the diffuser.

Recently, many investigations by different works highlighted the benefits augmented wind turbines [12-17]. Kosasih and Hudin [5] studied the performance of a small wind turbine without diffuser and diffuser-augmented micro wind turbine models subjected to different levels of turbulence. Based on their research, the diffuser increases the power coefficient by a factor of almost two [18].

More recent works are carried out on diffuser wind turbine. Ali and Kim [19] presented a study on an airborne lifted rotor blade modeled by imposing the elevated wind dataset while the outer shape is comprised of multi thick airfoils, the results showed that power gained by $21.3 \%$ using diffuser.

Watanabe and Ohya [20] presented a simple theory that only two coefficients are needed to predict the performance of wind lens turbine. The coefficients are the back pressure coefficient of the flange and the pressure recovery coefficient of the diffuser.

Bontempo et al., [21] investigated the performance of ducted wind turbines through a fully automated analysis procedure based on a CFD-Actuator-Disk approach. The method takes into account the effects of the design parameters, the rotor-duct coupling, the wake rotation and expansion, and the spanwise variability of the rotor load. The results showed that the chord and stagger angle of the duct contribute more than $85 \%$ to the improvements of the turbine performance, while the thickness has no effect.

Avallone et al., [22] described the flow and acoustic fields and how they are affected by the tipgap size. This is carried out by using lattice-Boltzmann Very-Large Eddy Simulation. Bontempo and 
Manna [23] presented a critical-analysis and review of the most important theoretical models conceived for the performance analysis and design of this wind enhancement system.

Dighe et al., [24] performed an aerodynamic and aeroacoustic analysis of diffuser wind turbine in yawed inflow condition for two duct geometries: a baseline commercial DWT model, DonQ ${ }^{\circledR}$, and one with a duct having a higher cross-section camber with respect to the baseline. The results showed placing the DWT at a yaw angle of $7.5^{\circ}$, the aerodynamic performances of the DonQi D5 DWT model are less affected by the yaw angle and increases of broadband noise.

Bontempo and Manna [25] presented a new momentum theory model with two-dimensional effects, the tip gap presence and a new free-wake ring-vortex method for the uniformly loaded ducted actuator disk. The results showed that ducted turbines can extract more power than a Betz disk with the same frontal area.

Vaz et al., [26] performed a new model for the finite number of blades in diffuser-augmented wind turbines. Optimization of chord and twist angle of shrouded blades was carried out using finite blade function. The results showed that the change in the finite blade function for the axial velocity has a large impact on the power-producing region near the tip and the change appears to make diffuser-augmented turbine power output less sensitive to tip speed ratio than for a bare turbine.

Rivarolo and Traverso [27] investigated the design of a ducted horizontal-axis wind turbine and to compare its produced energy with a traditional free turbine for energy harvesting, both at laboratory and on relevant environment scales. The model was designed considering a convergentdivergent duct, with the rotor in the throat section. The analysis with a yaw angle of $20^{\circ}$, it was founded a further increase in performance.

Al-Quraishi et al., [28] presented a small scale of flanged diffuser wind turbine with flange angle of $0^{\circ}$. The rotor was designed based on a modified blade element momentum theory, which adopts on developing the preliminary rotor blade geometry in terms of pitch angle. The power at a different wind velocity ranged $5-9 \mathrm{~m} / \mathrm{s}$ was calculated experimentally.

Base on the above literature survey, it is clear that few researchers concerned with the optimization of diffuser shape and effect of diffuser flange angle. The objective of current study can be listed as:

i. Validation with previous experimental and grid independent study of numerical model.

ii. A numerical parametric study was conducted on the diffuser to obtain the initial optimum form of flanged diffuser.

iii. The simplex algorithm is used to obtain the optimal diffuser shape starting from the obtained initial shape.

iv. Studding the effect of forward and backward flange angles on diffuser optimum shape.

v. Comparison between the power of a selected small wind turbine with and without the obtained diffuser shape.

\section{Diffuser Numerical Model and Boundary Conditions}

The diffuser has an inlet diameter, $\mathrm{D}$, of $0.4 \mathrm{~m}$ and the geometry of diffuser is defined by four variables; open angle, $\alpha$, flange height, $h$, centerbody length, $L$, and flange angle, $\beta$. The control volume of diffuser is the upper zone only bounded by the center line as the problem is two-dimension axisymmetric, as shown in Figure 1. The range of these dimensionless variables is tabulated in Table 1. 

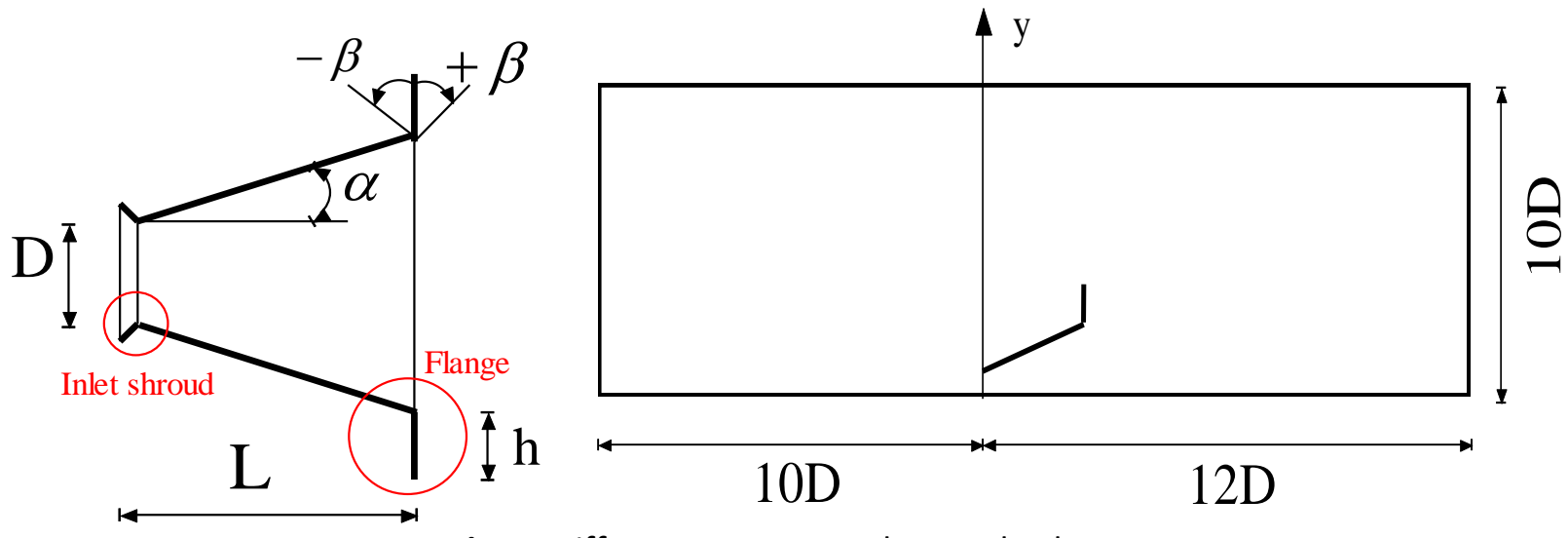

Fig. 1. Diffuser geometry and control volume

Table 1

The ranges of variables defined the diffuser

\begin{tabular}{llll}
\hline Variable & Minimum & step & Maximum \\
\hline L/D & 1 & 1 & 4 \\
h/D & 0.1 & 0.1 & 0.4 \\
$\alpha[\mathrm{deg}]$ & 4 & 2 & 16 \\
$\beta[\mathrm{deg}]$ & -30 & 15 & 30 \\
\hline
\end{tabular}

The computational domain has inlet and outlet farfield boundary with horizontal velocity, $\mathrm{u}_{\infty}$, of $4 \mathrm{~m} / \mathrm{sec}$ (Mach number $=0.012$ ). The centerline is symmetry boundary, as shown in Figure 2 . The problem solved at sea-level condition (Reynolds number $=1.1 \times 10^{5}$ ) using standard $\mathrm{k}-\varepsilon$ RNG turbulence model according the recommendations of previous studies by Mansour and Meskinkhoda [6], Aziz and Elsayed [29], Yusuf [30], Kamsah et al., [31], and Johnson et al., [32].

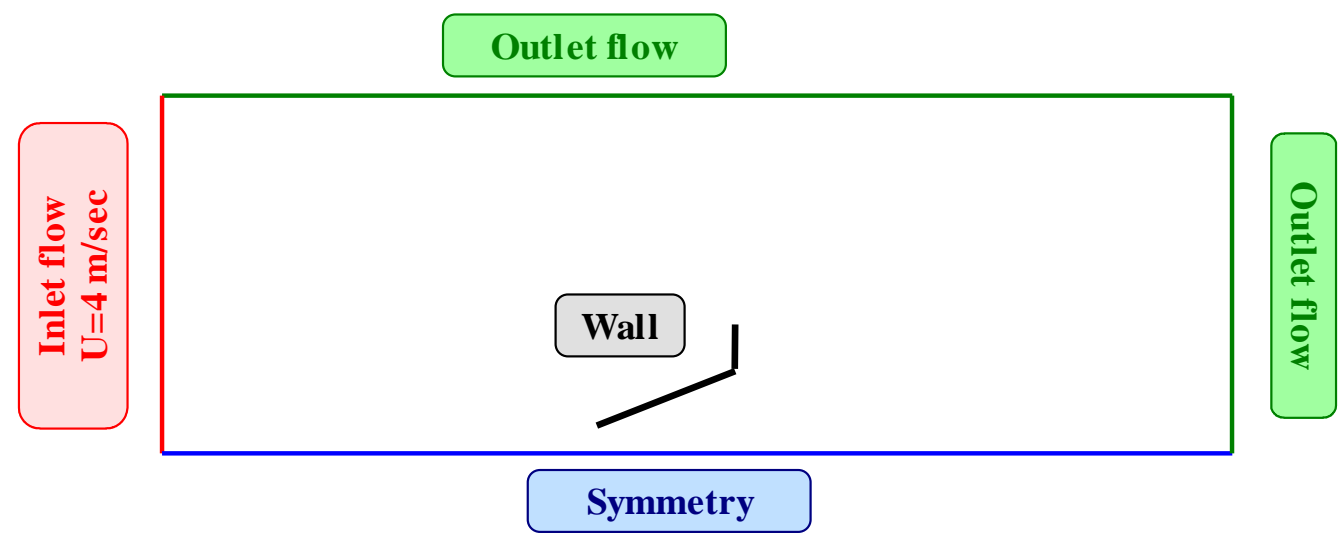

Fig. 2. Control volume boundary conditions

\section{Computational Model Grid Sensitivity Analysis and Model Validation}

A grid sensitivity analysis is conducted for a case study of diffuser having L/D of 2.5, h/D of 0.25 , and open angle of $12^{\circ}$. The results of changing the number of cells from 6200 cells up to 487000 on the average velocity, $u_{a v}$, at the diffuser inlet are plotted in Figure 3 . The results indicate that the inlet average velocity slightly changes for a grid size greater than 366000 cells. In addition, Figure 3 presents the effect of varying the number of cells on the velocity profiles (variation of local velocity magnitude, $u$, versus local diffuser inlet radius, $r$ ). The velocity profiles do not change much for grid size greater than 366000 . 


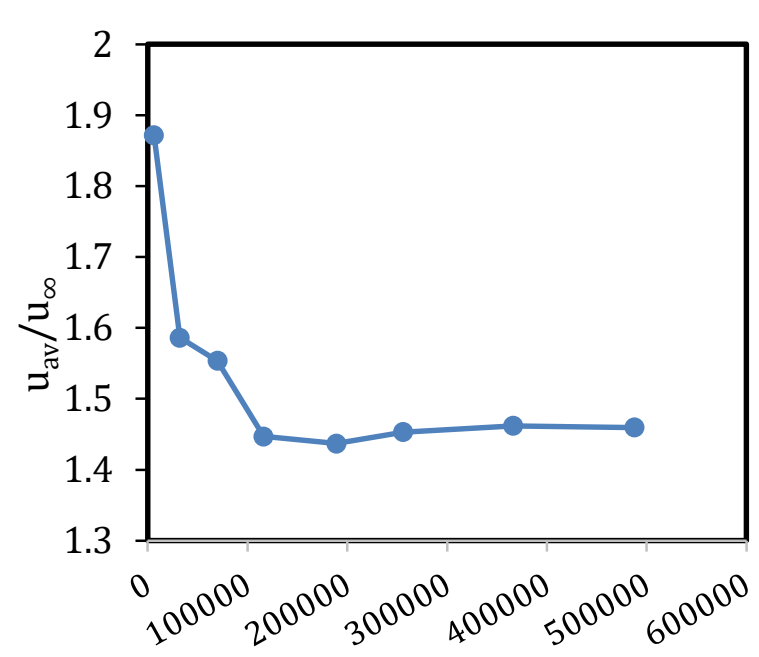

Number of cells

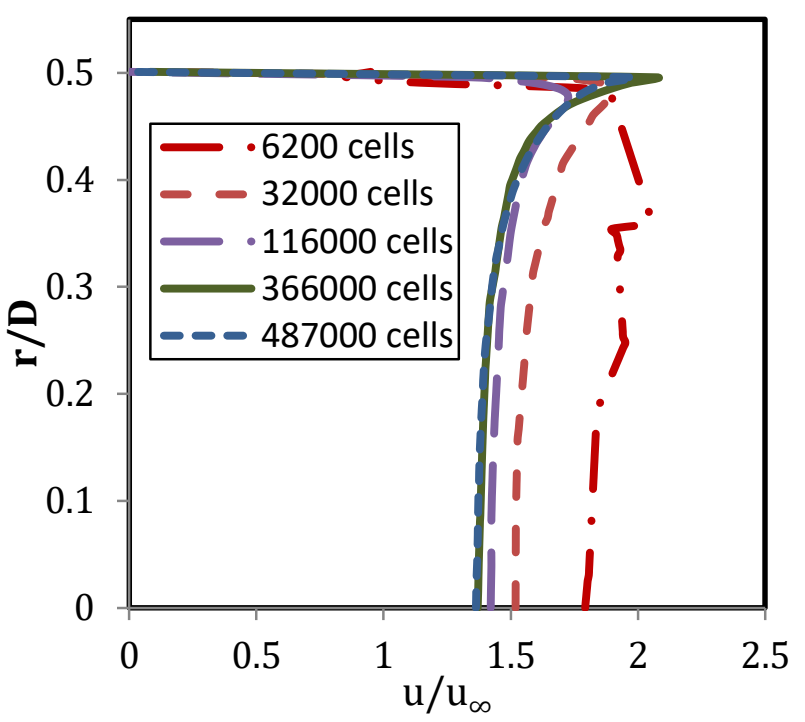

Fig. 3. Effect of the number of cells on the diffuser inlet average velocity and inlet velocity profile

Figure 4 presents the nondimensional quantity $\left(\mathrm{y}^{+}\right)$which expresses the density of grid on the diffuser wall surface of different numbers of control volume cells. The figure indicates that the value of $\mathrm{y}^{+}$not exceed two on the diffuser wall with cell number 366000 .

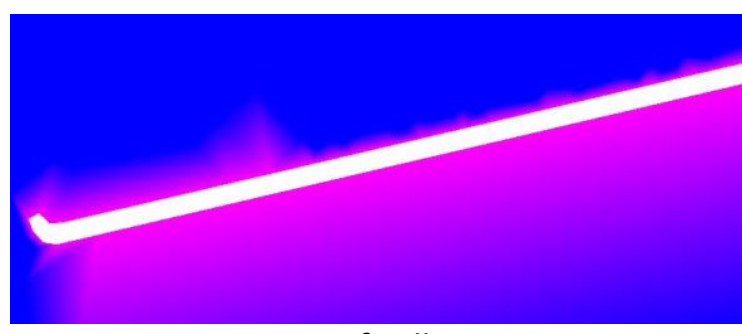

No. of cells $=6200$

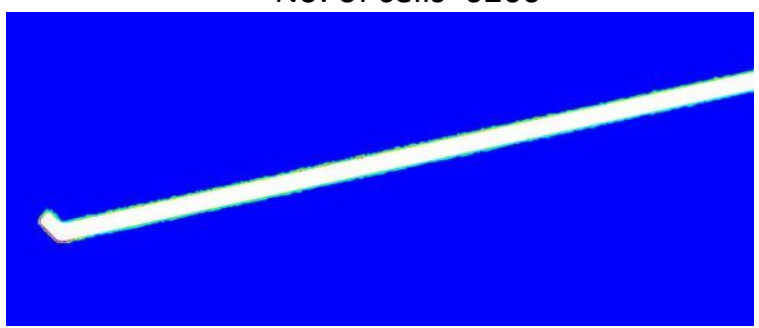

No. of cells $=116000$

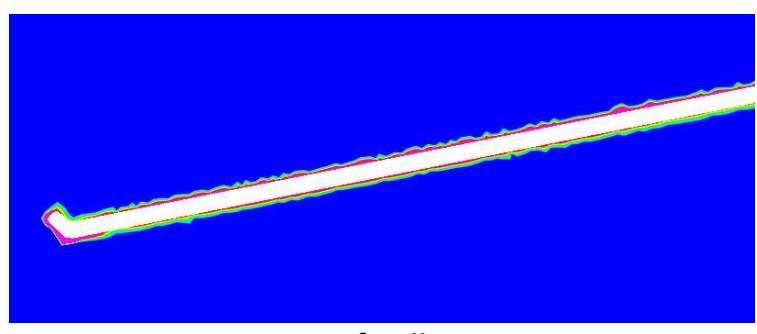

No. of cells $=32000$

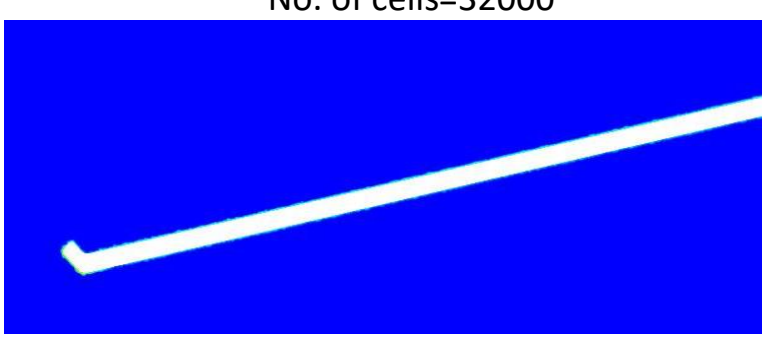

No. of cells $=366000$

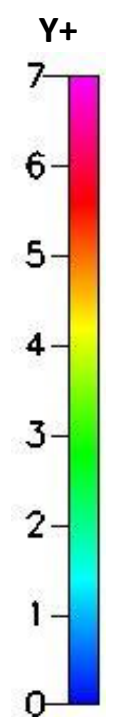

0

Fig. 4. Contours of $\mathrm{y}^{+}$at the diffuser inlet with different number of cells

The unstructured grid obtained from previous simulation of the diffuser is presented in Figure 5. The minimum cell size is $0.02 \mathrm{~mm}$ at the diffuser wall where the maximum cell size is $0.8 \mathrm{~m}$ at farefield boundary with transition factor 1.1 . 

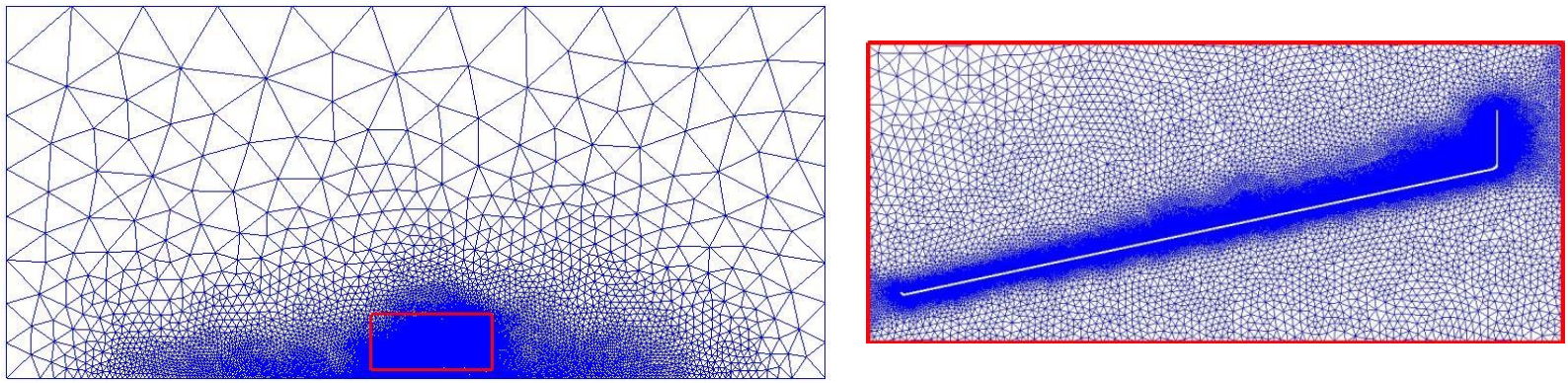

Fig. 5. Diffuser control volume unstructured grid of 366000 cells

The current results are numerically validated with another numerical study by Mansour and Meskinkhoda [6] and experimental testing by Abe and Ohya [7] of similar geometry. The diffuser has length, $L / D=1.5$, height, $h / D=0.5$, and open angle $4^{\circ}$. Figure 6 presents a comparison between the velocity contours of current study and pervious work by Mansour and Meskinkhoda [6] in additions a stream wise velocity distribution on $x$-axis of current and previous works. The results showed acceptable level of agreement.
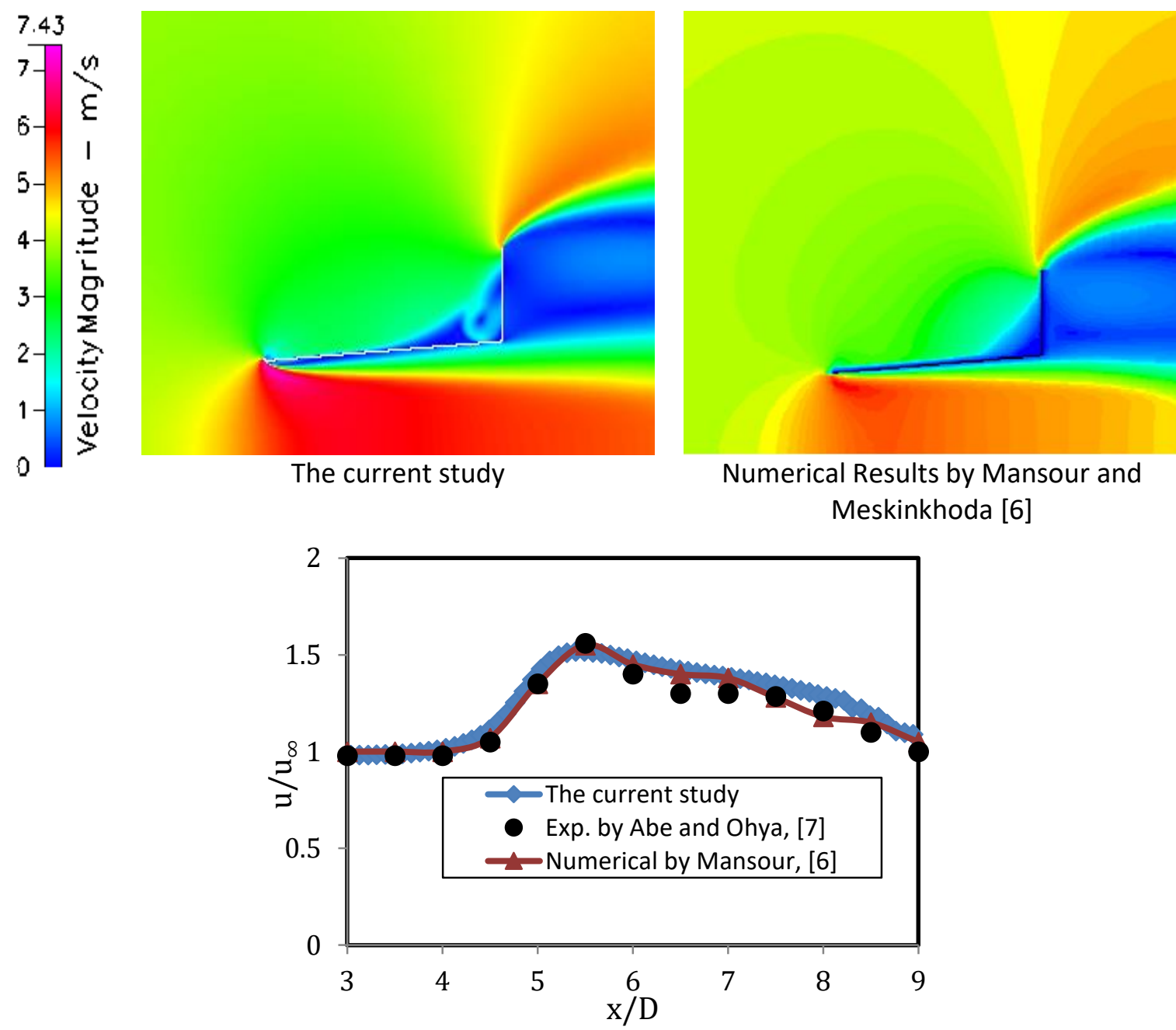

Fig. 6. Comparison between the velocity of current numerical work and previous numerical and experimental works 


\section{Optimum Diffuser Shape using Parametric Study \\ 4.1 Effect of Diffuser Length}

Figure 7 presents the effect of diffuser geometry (open angle, flange height, and centerbody length) with zero flange angles on the diffuser average entrance velocity. It is clear from different Figure 7 (a) to Figure 7 (d) that by increasing the diffuser length, the diffuser entrance velocity is enhanced for different flange heights and open angles. The increase of diffuser length increases the pressure drop between the diffuser entrance and exit sections therefore increases diffuser entrance velocity. The entrance velocity slightly changes for diffuser length greater than $L / D=3$ Figure 7 (c) and Figure $7(d)$ or remains constant with a diffuser has a flange height of $h / D=0.4$, where no significant pressure difference.

\subsection{Effect of Diffuser Flange Height}

The wind speed increases near the diffuser entrance when a large flange is attached to the outer periphery of a diffuser exit. The flow is from left to right, and the vortex formation like the Karman vortex street is seen downstream of the flange. The static back pressure in the exit area of the diffuser equipped with a flange falls to a fairly low pressure compared to that of the upstream flow which enhances the entrance velocity. The effect of flange height on the velocity magnitude is presented in Figure 8 . The entrance velocity is enhanced by increasing the flange height up to height $h=0.4 \mathrm{D}$ where no significant change in exit velocity or exit pressure. Figure 7 indicates also the best flange height differs with different diffuser lengths. At short diffuser ( $L / D=1.5$ or 2 ), the best flange height is $h / D$ $=0.3$, at intermediate diffuser $(L / D=3)$, the best flange height is $h / D=0.4$. The best flange height decreases with long diffuser to reach $h / D=0.2$ at diffuser length $L / D=4$.

\subsection{Effect of Diffuser Open Angle}

As shown in Figure 7, the entrance velocity of different diffuser lengths and flange heights increased more steeply in angles of more than $4^{\circ}$ up to a certain angle according the diffuser length. The best diffuser open angle was $8^{\circ}$ for short diffuser and $6^{\circ}$ for short diffuser $(L / D=2)$ with long flange height $(\mathrm{h} / \mathrm{D}=0.3 \& 0.4)$, intermediate and long diffusers where the flow separation inside the diffuser increases after these best open angles.

Based on the previous parametric study the optimum diffuser shape which maximize the average entrance velocity to $1.73 \mathrm{u}_{\infty}$ has length $(L / D=4)$, flange height $(h / D=0.2)$, and open angle $6^{\circ}$. Although, the optimum diffuser has long length (4D) is suitable practically with small wind turbine.

\section{Optimum Diffuser Shape Using Simplex Algorithm}

The details of optimization process using simplex algorithm was presented by Elsayed et al., [33] and Elsayed et al., [34] in previous works. A simplex is a polygon defined by $\mathrm{N}+1$ vertices in $\mathrm{N}$ dimensional space. For example, in 2D, a simplex is a triangle, as shown in Figure 9. Each vertex of the polygon represents a single design configuration, with design variable values $x_{1}, x_{2}, \ldots, x_{N}$ with a corresponding objective function value. To progress towards an optimum solution, the simplex algorithm reflects the vertex associated with the worst design through the centroid of the polygon. New design variable values and the associated objective function value define the new point. 

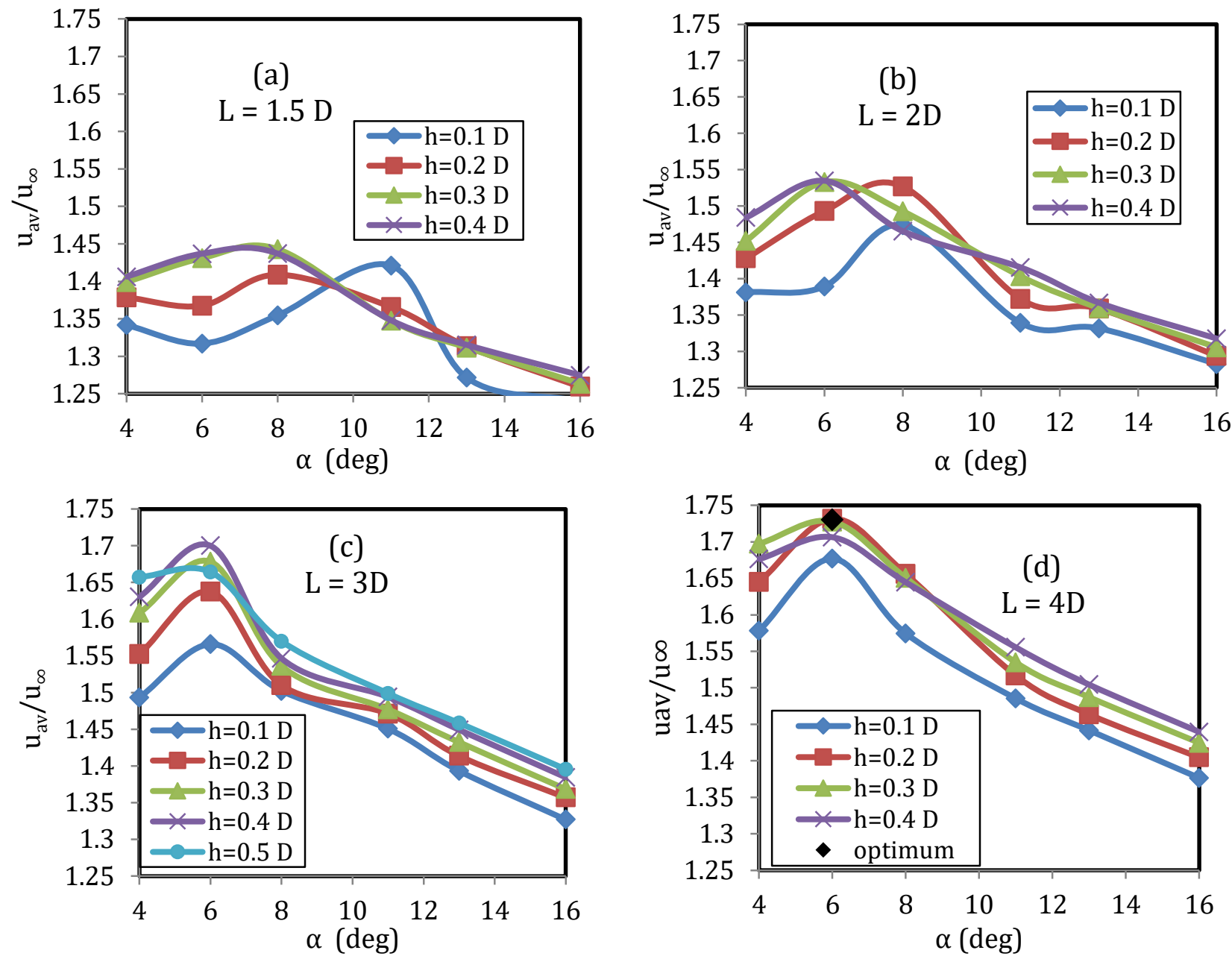

Fig. 7. Effect of diffuser geometry on the average entrance velocity with zero flange angle

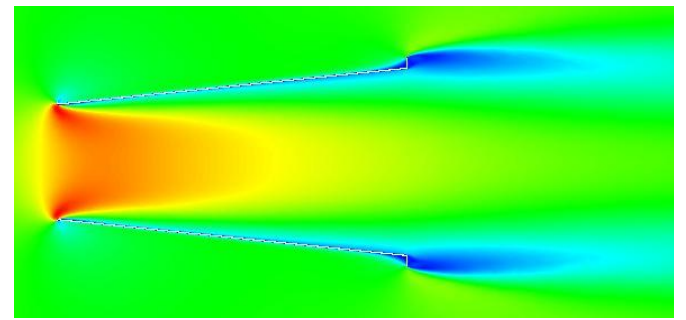

$h / D=0.1$

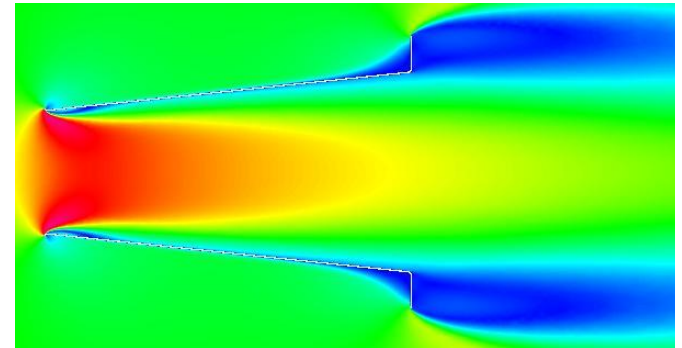

$h / D=0.3$

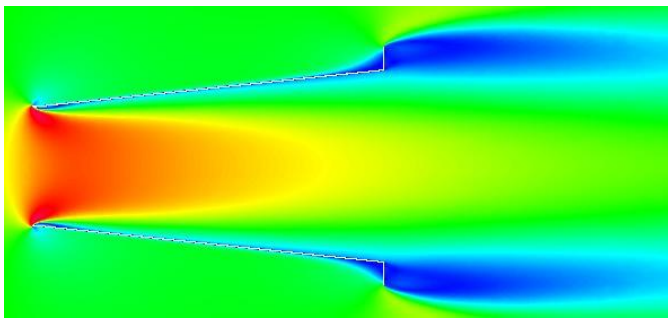

$$
h / D=0.2
$$

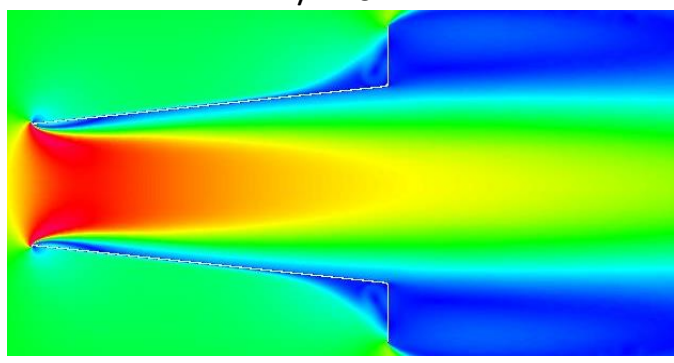

$h / D=0.5$

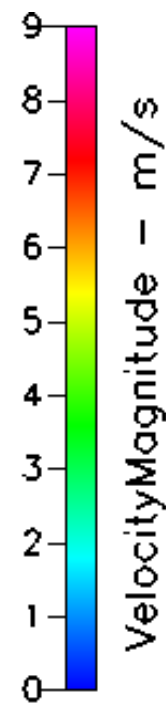

Fig. 8. Contours of velocity magnitude of different diffuser height with $L / D=3, \alpha=6^{\circ} \& \beta=0^{\circ}$ 

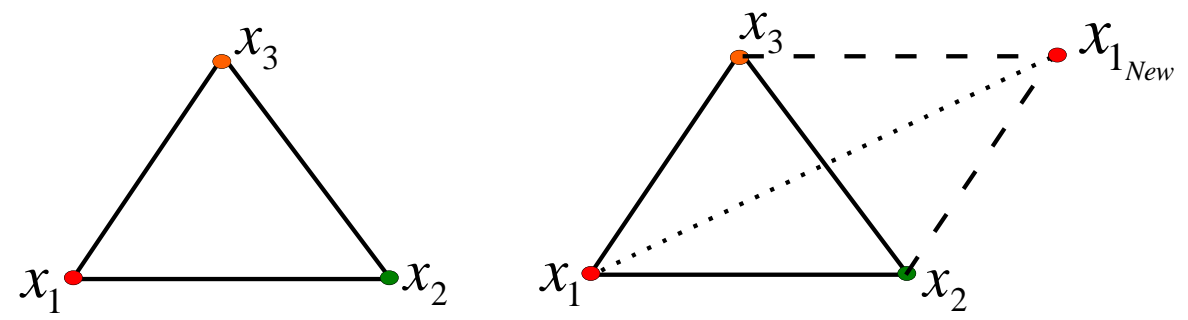

Fig. 9. A new design point is obtained by reflecting the worst design through the centroid of the remaining points

The objective function which optimized in the current study is the diffuser average entrance velocity. The search area of the variables defines the diffuser shape (the constraints) is tabulated in Table 1. By defining the maximum number of iterations (100 iterations) and precision (the difference between the current iteration and previous one $=10^{-4}$ ), the optimization process is started with the obtained shape from the parametric study. After 53 iterations the optimizer reached the optimum diffuser shape as shown in Figure 10. The obtained shape can maximize the diffuser entrance average velocity to $1.763 \mathrm{u}_{\infty}$. The variables define the optimum diffuser shape are compared with starting variables in Table 2, and the two shapes are plotted in Figure 11.

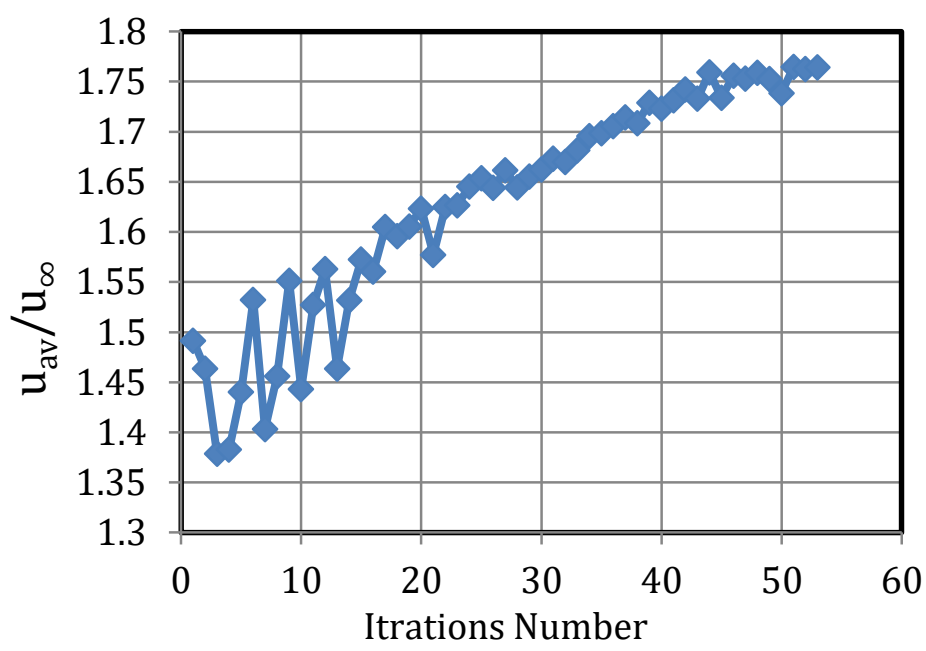

Fig. 10. Optimization history using simplex algorithm

Table 2

Comparison between the variables define the two diffuser shapes

\begin{tabular}{llllll}
\hline & Iteration & L/D & h/D & $\alpha$ & $\mathrm{U}_{\text {av }} / \mathrm{U}_{\infty}$ \\
\hline Parametric study & ---- & 4 & 0.2 & $6^{\circ}$ & 1.73 \\
Simplex algorithm & 53 & 3.94 & 0.29 & $5.47^{\circ}$ & 1.763 \\
\hline
\end{tabular}

Optimum diffuser using parametric

Optimum diffuser using Simplex algorithm

Fig. 11. Comparison between the two diffuser shapes 


\section{Effect of Flange Angle on The Diffuser Optimum Shape}

In this section, the effect of flange angle in forward and backward directions is presented. As mentioned before the existence of vortex behind the flange of diffuser exit plays an important role in suction extra flow inside the diffuser. The strength of the vortex changes by varying the flange angle. Figure 12 presents the streamline contours of different flange angles; the forward flange angles (+ve) enhance the vortices after the diffuser exit $\left(\beta=15 \& 30^{\circ}\right)$. But, the increase of forward flange angle than $30^{\circ}$ changes the flow direction which touches the flange in forward direction hence eliminate the vortex or increase the diffuser exit pressure. The backward flange angle (-ve) enhances the vortices in the other side of flange without any positive effect on the diffuser exit flow.
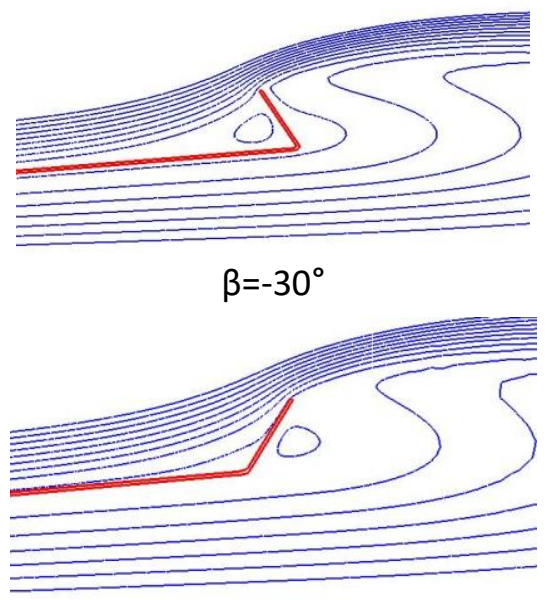

$\beta=30^{\circ}$

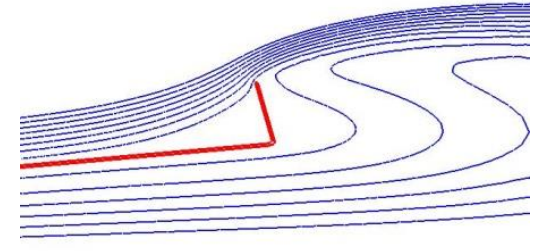

$\beta=-15^{\circ}$

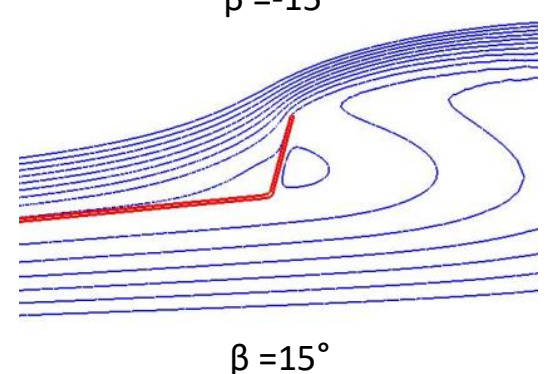

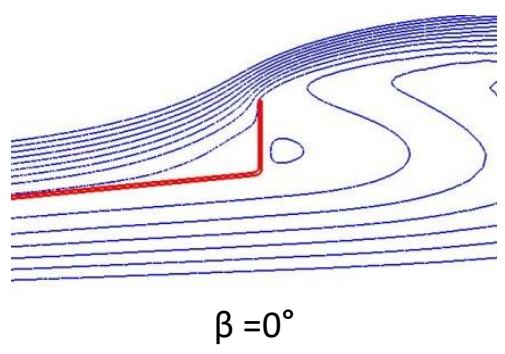

$\beta=0^{\circ}$

Fig. 12. Streamlines contours of optimum diffuser shape at different flange angles

Figure 13 presents the effect of the diffuser flange angle on the diffuser average entrance velocity. It is clear that the forward flange angle can increase the average entrance velocity than the obtained value with zero flange angle to reach $1.77 \mathrm{u}_{\infty}$ at the diffuser with $15^{\circ}$ forward flange angle. But the backward flange angle decreases the diffuser entrance average velocity by decreasing the vortices at the diffuser exit plane.

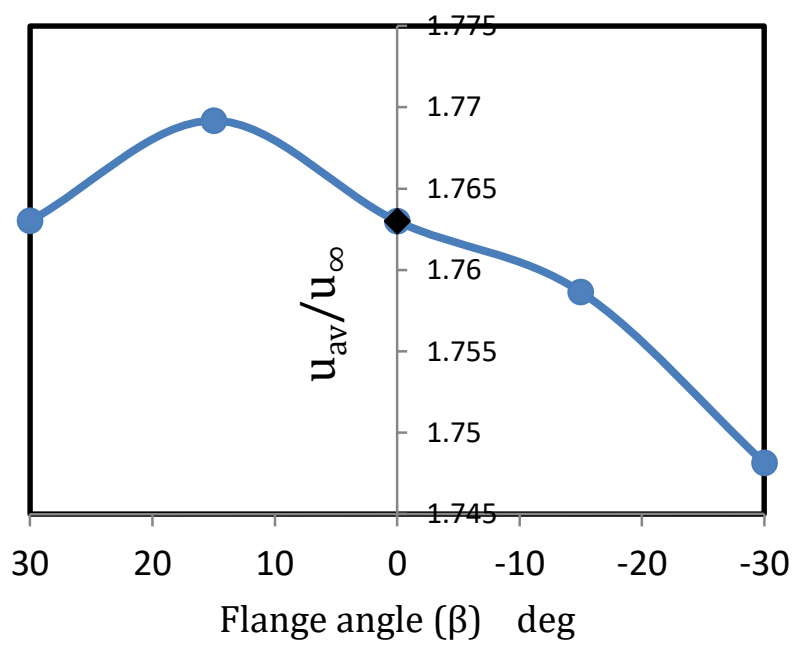

Fig. 13. The effect of the diffuser flange angle on the diffuser average entrance velocity 


\section{Performance of Obtained Diffuser Shape with Wind Turbine}

The obtained diffuser without rotor is used with selected small wind turbine, since the diffuser changes the velocity field at the rotor inlet, the velocity triangles of the rotor also change, so that the rotor cannot still work in an optimum condition. But, the aim of this section to examine the effect of obtained diffuser on wind turbine.

The selected small wind turbine was designed using Blade Element Momentum theory [35]. The blade has NACA-4412 airfoil section with a hub radius, $r_{h}$, of $0.02 \mathrm{~m}$, tip radius, $r_{t}$, of $0.2 \mathrm{~m}$ and three blades, as shown in Figure 14(a).

The control volumes of one blade with and without the obtained diffuser shape are shown in Figure 14(b) and Figure 14(c). The upstream and the upper stream boundaries located at fifth times the blade length; the downstream boundary located at 15 times the blade length. Due to complex geometry of problem unstructured grid are used with two different zones; the first zone is the blade or blade with diffuser zone had refined grid near the turbine blade profile and diffuser wall to obtain the effect of boundary layer and accurate results, the second zone is the external zone with course grid at the farefield boundaries.

Figure 14(d) presents the control volume unstructured grid based on the obtained minimum cell size, maximum cell size and transition factor of two dimensional study to adjust the value of $\mathrm{y}^{+}$around two. For the control volume with blade only the number of cells reached one million cells while the number of cells reached 1.46 million cells for blade with diffuser.

Figure 14(e) presents the boundary conditions of problem. The single rotating frame of reference technique in the ACE solver is used to simulate the problem. The upstream inlet is specified to be a free stream velocity inlet with speed range $3: 10 \mathrm{~m} / \mathrm{sec}$ (cut in: cut out speed) and sea level properties while the upper stream and downstream are outlet farefield boundaries with sea level properties. The blade and shaft are rotating walls and the other walls (diffuser surface) are kept stationary. A periodic (cyclic) boundary condition is specified for both sides of two zones. The blade-tip-speed ratio is 4 and the blade rotational speed, $\omega$, can be calculated at different wind speeds.

The goal of this study was to find the torque, generated due to the flow, driving the wind turbine blade inside the obtained diffuser shape and compare this torque and obtained power with these of wind turbine without diffuser. The variation of turbine performance characteristics are investigated numerically at different wind speeds, such as turbine output power, P, using Eq. (1):

$$
P=T \omega
$$

Where, $\mathrm{T}$ is the torque generated on the three blades (N.m) and the turbine power coefficient is given by Eq. (2) and Eq. (3):

$$
\begin{aligned}
& C_{p t}=P /\left(1 / 2 \rho u_{\infty}^{3} S_{t}\right) \\
& C_{p d}=P /\left(1 / 2 \rho u_{\infty}^{3} S_{d}\right)
\end{aligned}
$$

where $S_{t}$ is the area of wind turbine rotor $\left(S_{t}=\pi r_{t}^{2}\right)$ and $S_{d}$ is the optimum diffuser largest projected area are investigated numerically at different wind speeds. 

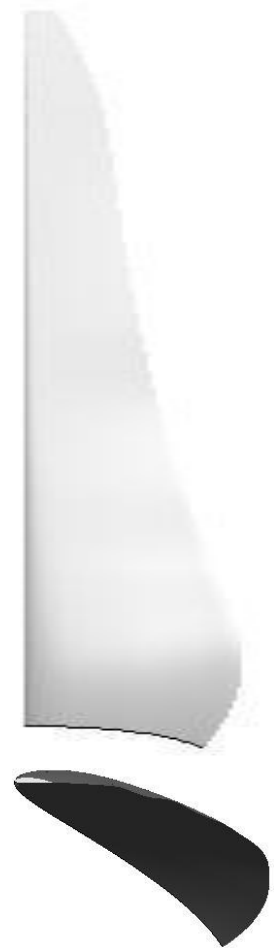

(a) Wind turbine 3D views

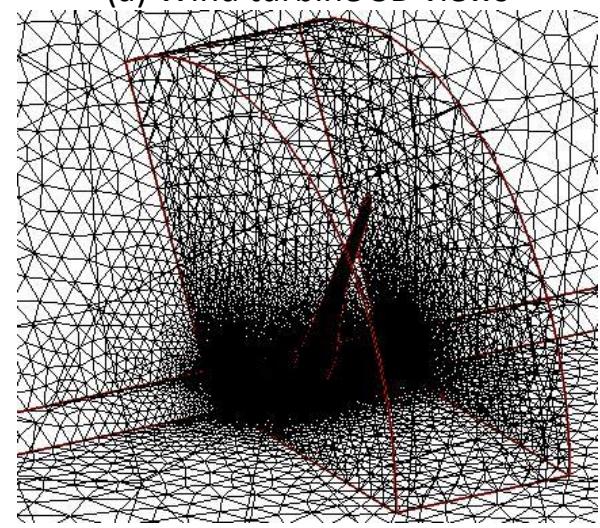

(d) Blade zoom Unstructured grid

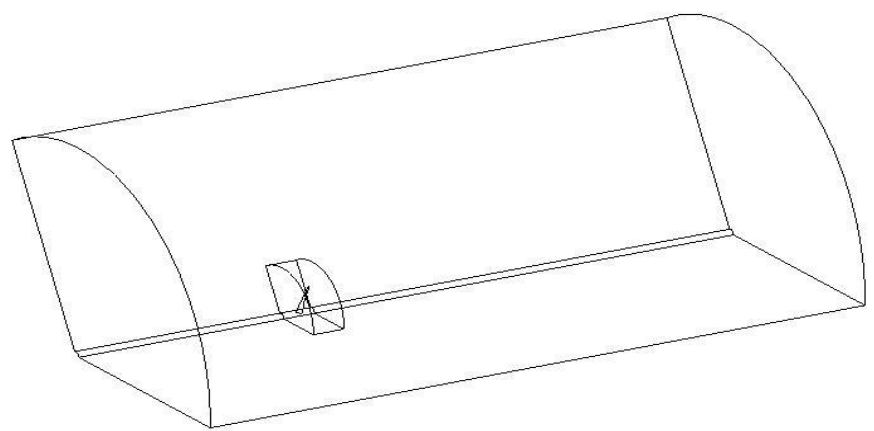

(b) Wind turbine control volume

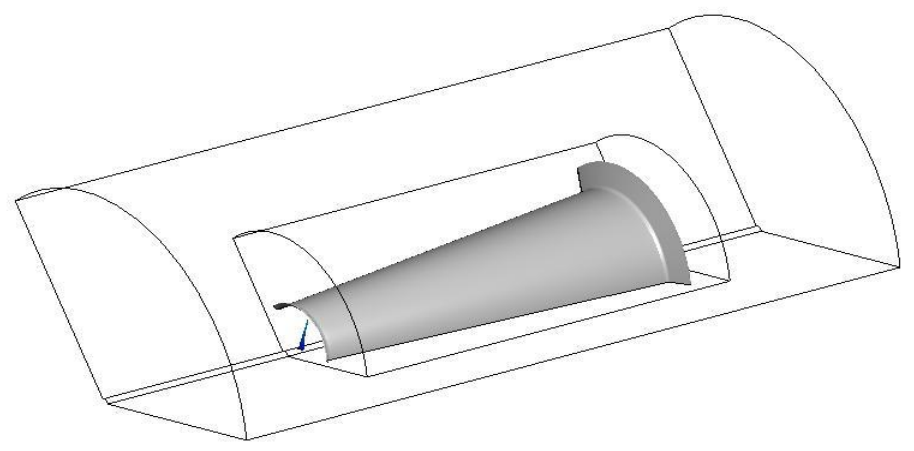

(c) Wind turbine with obtained diffuser control volume

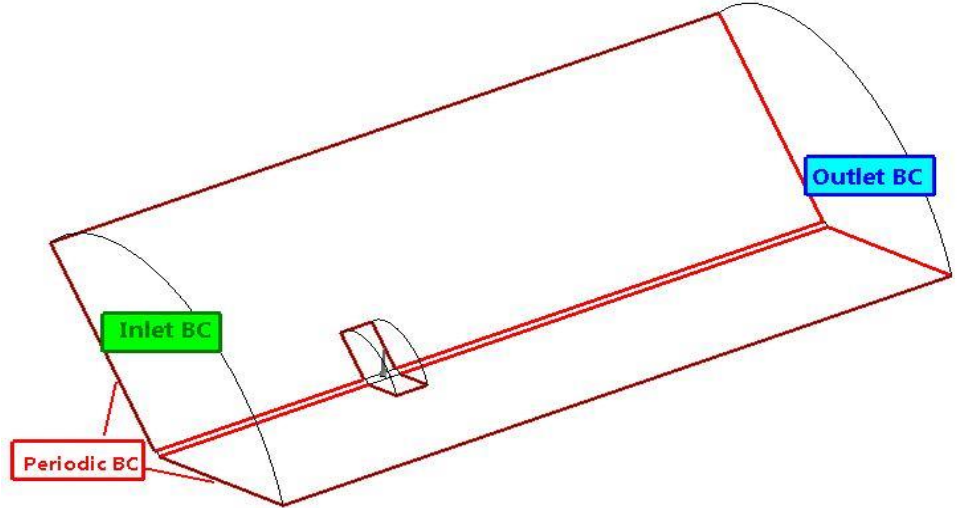

(e) Control volume Boundary conditions

Fig. 14. The wind turbine with and without diffuser geometry, grid and boundary conditions

Figure 15 presents the output power generation and power coefficient variation with different air speeds of a small wind turbine without and with obtained diffuser shape. As shown in figure the power of turbine increases by increasing the airspeed and this power is augmented by a factor of 2.76:5.26 using the obtained diffuser shape. The design point of obtained diffuser at wind speed of 4 $\mathrm{m} / \mathrm{s}$, the power of the small turbine is 2.42 Watt and by using the diffuser the power of turbine reached 6.75 Watt (i.e., the power augmented approximately by 2.8 the obtained power without diffuser). The output power of turbine is augmented due to increase the torque of blade in addition increase the rotational speed of turbine. 

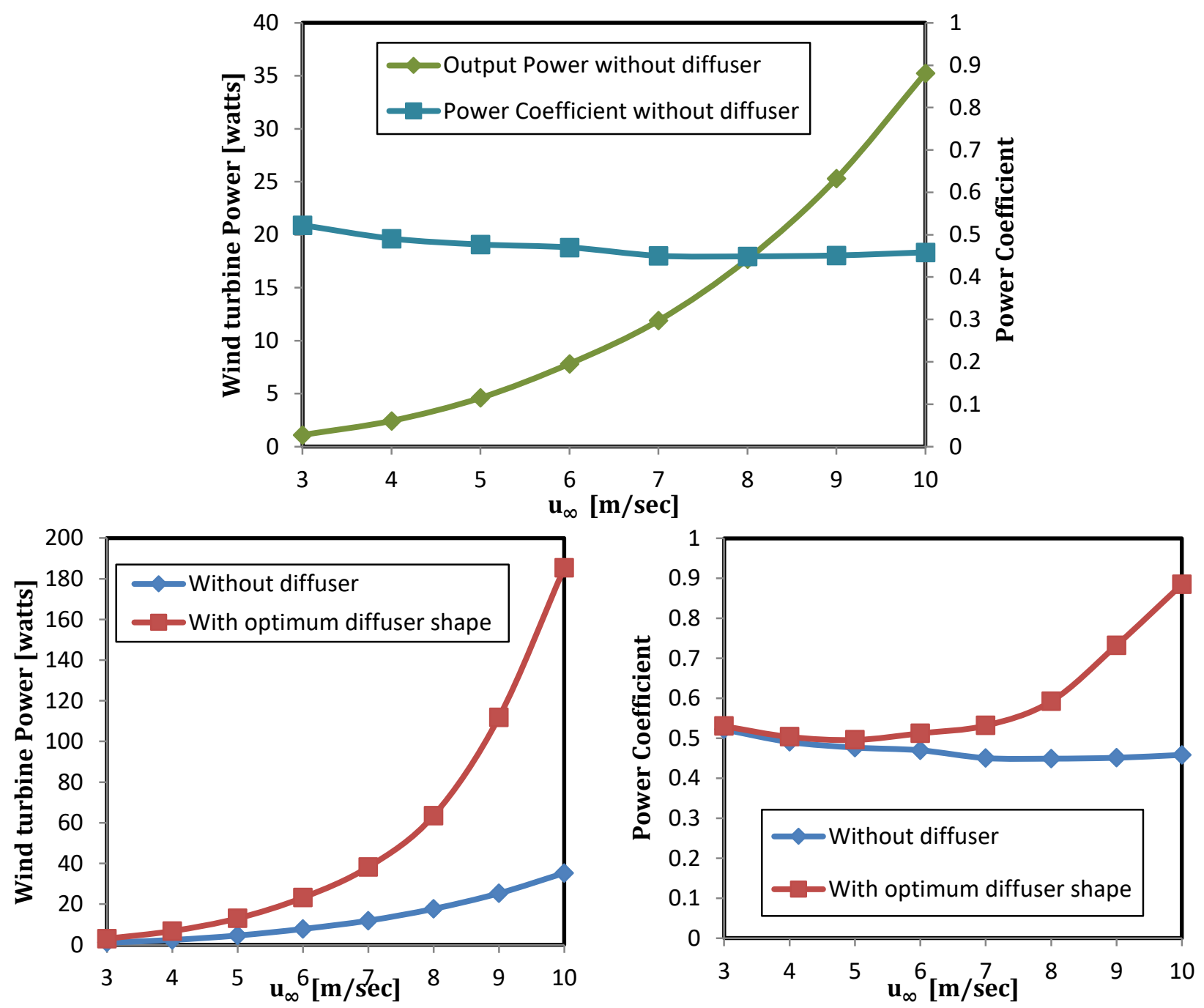

Fig. 15. The power and power coefficient variations of wind turbine without and with obtained diffuser shape at different wind speeds

\section{Conclusion}

The diffuser wind turbine has an important affect in enhancement the velocity at the entrance of diffuser therefore increases the wind turbine power. The increase in the diffuser entrance velocity can be maximized by obtaining the optimum shape of diffuser, which defined in this research by diffuser open angle, flange height, centerbody length and flange angle. Concluding points of this work are summarized as:

i. The results of parametric study indicate that the increase in diffuser length increases the pressure drop between the diffuser entrance and exit sections therefore increases diffuser entrance velocity with slightly changes for diffuser length greater than $L / D=3$. The flange at the diffuser end forms a vortex like the Karman vortex which decreases the pressure at this region. The strength of this vortex is increased by increasing the flange height up certain length according to the diffuser length.

ii. The best flange height, at short diffuser ( $L / D=1.5$ or 2 ) is $h / D=0.3$, at intermediate diffuser $(L / D=3)$, the best flange height is $h / D=0.4$. The best flange height decreases to reach $h / D=0.2$ with long diffuser $(L / D=4)$. The best diffuser open angle is in range between $6^{\circ}$ (for intermediate and long diffusers) and $8^{\circ}$ for short diffuser. 
iii. The optimum diffuser shape is obtained using simplex algorithm with length $(L / D=3.94)$, flange height $(h / D=0.29)$, and open angle $5.47^{\circ}$. The obtained shape can maximize the diffuser entrance average velocity to $1.763 \mathrm{u}_{\infty}$.

iv. The effect of flange angle on average entrance velocity is studded. Using the optimum diffuser with $15^{\circ}$ forward flange angle can increase the average velocity to $1.77 \mathrm{u}_{\infty}$.

v. The output power of a selected small wind turbine with obtained diffuser is augmented by a factor about 2.76:5.26 compared to that without diffuser.

\section{References}

[1] Aranake, Aniket C., Vinod K. Lakshminarayan, and Karthik Duraisamy. "Computational analysis of shrouded wind turbine configurations using a 3-dimensional RANS solver." Renewable Energy 75 (2015): 818-832. https://doi.org/10.1016/i.renene.2014.10.049

[2] Bet, F., and H. Grassmann. "Upgrading conventional wind turbines." Renewable Energy 28, no. 1 (2003): 71-78. https://doi.org/10.1016/S0960-1481(01)00187-2

[3] Nagai, Minoru, and Kunio Irabu. "Momentum theory of diffuser augmented wind turbine." Nippon Kikai Gakkai Ronbunshu, B Hen;(Japan) 53, no. 489 (1987): 1543-1547. https://doi.org/10.1299/kikaib.53.1543

[4] Jafari, Seyed AH, and Buyung Kosasih. "Flow analysis of shrouded small wind turbine with a simple frustum diffuser with computational fluid dynamics simulations." Journal of Wind Engineering and Industrial Aerodynamics 125 (2014): 102-110. https://doi.org/10.1016/i.jweia.2013.12.001

[5] Kosasih, Buyung, and H. Saleh Hudin. "Influence of inflow turbulence intensity on the performance of bare and diffuser-augmented micro wind turbine model." Renewable Energy 87 (2016): 154-167. https://doi.org/10.1016/i.renene.2015.10.013

[6] Mansour, Kamyar, and Peyman Meskinkhoda. "Computational analysis of flow fields around flanged diffusers." Journal of Wind Engineering and Industrial Aerodynamics 124 (2014): 109-120. https://doi.org/10.1016/j.jweia.2013.10.012

[7] Abe, Ken-ichi, and Yuji Ohya. "An investigation of flow fields around flanged diffusers using CFD." Journal of Wind Engineering and Industrial Aerodynamics 92, no. 3-4 (2004): 315-330. https://doi.org/10.1016/i.jweia.2003.12.003

[8] Matsushima, Toshio, Shinya Takagi, and Seiichi Muroyama. "Characteristics of a highly efficient propeller type small wind turbine with a diffuser." Renewable Energy 31, no. 9 (2006): 1343-1354. https://doi.org/10.1016/i.renene.2005.07.008

[9] Gilbert, Barry L., Richard A. Oman, and Kenneth M. Foreman. "Fluid dynamics of diffuser-augmented wind turbines." Journal of Energy 2, no. 6 (1978): 368-374. https://doi.org/10.2514/3.47988

[10] Gilbert, B. L., and K. M. Foreman. "Experiments with a diffuser-augmented model wind turbine." Trans. ASME Journal of Energy Resources Technology 105, no. 1 (1983): 46-53. https://doi.org/10.1115/1.3230875

[11] Igra, Ozer. "Research and development for shrouded wind turbines." Energy Conversion and Management 21, no. 1 (1981): 13-48. https://doi.org/10.1016/0196-8904(81)90005-4

[12] Shonhiwa, Chipo, and Golden Makaka. "Concentrator augmented wind turbines: a review." Renewable and Sustainable Energy Reviews 59 (2016): 1415-1418. https://doi.org/10.1016/i.rser.2016.01.067

[13] Khamlaj, Tariq Abdulsalam, and Markus Peer Rumpfkeil. "Analysis and optimization of ducted wind turbines." Energy 162 (2018): 1234-1252. https://doi.org/10.1016/i.energy.2018.08.106

[14] Wong, Kok Hoe, W. T. Chong, H. T. Yap, A. Fazlizan, W. Z. W. Omar, S. C. Poh, and F. B. Hsiao. "The design and flow simulation of a power-augmented shroud for urban wind turbine system." Energy Procedia 61 (2014): 1275-1278. https://doi.org/10.1016/j.egypro.2014.11.1080

[15] Nobile, Rosario, Maria Vahdati, Janet F. Barlow, and Anthony Mewburn-Crook. "Unsteady flow simulation of a vertical axis augmented wind turbine: A two-dimensional study." Journal of Wind Engineering and Industrial Aerodynamics 125 (2014): 168-179. https://doi.org/10.1016/i.jweia.2013.12.005

[16] Liu, Yingyi, and Shigeo Yoshida. "An extension of the Generalized Actuator Disc Theory for aerodynamic analysis of the diffuser-augmented wind turbines." Energy 93 (2015): 1852-1859. https://doi.org/10.1016/i.energy.2015.09.114

[17] Khattak, M. A., N. S. Mohd Ali, N. H. Zainal Abidin, N. S. Azhar, and M. H. Omar. "Common Type of Turbines in Power Plant: A Review." Journal of Advanced Research in Applied Sciences and Engineering Technology 3, no. 1 (2016): 77100.

[18] Kosasih, Buyung, and H. Saleh Hudin. "Influence of inflow turbulence intensity on the performance of bare and diffuser-augmented micro wind turbine model." Renewable Energy 87 (2016): 154-167. https://doi.org/10.1016/j.renene.2015.10.013 
[19] Ali, Qazi Shahzad, and Man-Hoe Kim. "Design and performance analysis of an airborne wind turbine for highaltitude energy harvesting." Energy 230 (2021): 120829. https://doi.org/10.1016/i.energy.2021.120829

[20] Watanabe, Koichi, and Yuji Ohya. "A Simple Theory and Performance Prediction for a Shrouded Wind Turbine with a Brimmed Diffuser." Energies 14, no. 12 (2021): 3661. https://doi.org/10.3390/en14123661

[21] Bontempo, R., R. Carandente, and M. Manna. "A design of experiment approach as applied to the analysis of diffuser-augmented wind turbines." Energy Conversion and Management 235 (2021): 113924. https://doi.org/10.1016/i.enconman.2021.113924

[22] Avallone, Francesco, Daniele Ragni, and Damiano Casalino. "On the effect of the tip-clearance ratio on the aeroacoustics of a diffuser-augmented wind turbine." Renewable Energy 152 (2020): 1317-1327. https://doi.org/10.1016/j.renene.2020.01.064

[23] Bontempo, R., and M. Manna. "Diffuser augmented wind turbines: Review and assessment of theoretical models." Applied Energy 280 (2020): 115867. https://doi.org/10.1016/i.apenergy.2020.115867

[24] Dighe, Vinit V., Francesco Avallone, and Gerard van Bussel. "Effects of yawed inflow on the aerodynamic and aeroacoustic performance of ducted wind turbines." Journal of Wind Engineering and Industrial Aerodynamics 201 (2020): 104174. https://doi.org/10.1016/i.jweia.2020.104174

[25] Bontempo, R., and M. Manna. "On the potential of the ideal diffuser augmented wind turbine: an investigation by means of a momentum theory approach and of a free-wake ring-vortex actuator disk model." Energy Conversion and Management 213 (2020): 112794. https://doi.org/10.1016/i.enconman.2020.112794

[26] Vaz, Jerson RP, Valery L. Okulov, and David H. Wood. "Finite blade functions and blade element optimization for diffuser-augmented wind turbines." Renewable Energy $165 \quad$ (2021): 812-822. https://doi.org/10.1016/i.renene.2020.11.059

[27] Rivarolo, M., A. Freda, and A. Traverso. "Test campaign and application of a small-scale ducted wind turbine with analysis of yaw angle influence." Applied Energy $279 \quad$ (2020): 115850. https://doi.org/10.1016/i.apenergy.2020.115850

[28] Al-Quraishi, Balasem Abdulameer Jabbar, Sofian Mohd, Aghssan Mohammed Nwehil, Nor Zelawati Asmuin, Mohammed N. Nemah, Dhafer M. Hachim, Hyder H. Balla, Salih Meri, and M. N. Hidayat. "Improvement of a Flanged Diffuser Augmented Wind Turbine Performance by Modifying the Rotor Blade Aerodynamic Design." Journal of Advanced Research in Fluid Mechanics and Thermal Sciences 72, no. 1 (2020): $124-137$. https://doi.org/10.37934/arfmts.72.1.124137

[29] Aziz, M. A., and A. M. Elsayed. "CFD Investigations for UAV and MAV low speed airfoils characteristics." International Review of Aerospace Engineering (IREASE) 8, no. 2 (2015). https://doi.org/10.15866/irease.v8i3.6212

[30] Yusuf, Siti Nurul Akmal, Yutaka Asako, Nor Azwadi Che Sidik, Saiful Bahri Mohamed, and Wan Mohd Arif Aziz Japar. "A Short Review on RANS Turbulence Models." CFD Letters 12, no. 11 (2020): 83-96. https://doi.org/10.37934/cfdl.12.11.8396

[31] Kamsah, Nazri, Haslinda Mohamed Kamar, Muhammad Idrus Alhamid, and Wong Keng Yinn. "Impacts of temperature on airborne particles in a hospital operating room." Journal of Advanced Research in Fluid Mechanics and Thermal Sciences 44, no. 1 (2018): 12-23.

[32] Johnson, Zwalnan Selfa, Abakar Yousif Abdalla, Shanmugam Anandan, Chan Andy Tak-Yee, and Su Yuehong. "A Numerical Evaluation of the Effect of Building Thermal Load on the Overall Performance Characteristic of a GridCoupled PV/T Energy System." Journal of Advanced Research in Numerical Heat Transfer 4, no. 1 (2021): 32-43.

[33] Aziz, M. A., and A. M. Elsayed. "Numerical investigation and optimization of airfoil flow control using passive airjet." Thermophysics and Aeromechanics 26, no. 3 (2019): 361-374. https://doi.org/10.1134/S0869864319030053

[34] Elsayed, Ahmed M., Farouk M. Owis, and M. Madbouli Abdel Rahman. "Film cooling optimization using numerical computation of the compressible viscous flow equations and simplex algorithm." International Journal of Aerospace Engineering 2013 (2013). https://doi.org/10.1155/2013/859465

[35] Khaled, Mohamed, Mostafa Mohamed Ibrahim, Hesham ElSayed Abdel Hamed, and Ahmed Farouk Abdel Gawad. "Aerodynamic design and blade angle analysis of a small horizontal-axis wind turbine." American Journal of Modern Energy 3, no. 2 (2017): 23-37. https://doi.org/10.11648/i.ajme.20170302.12 